The Journal of Animal \& Plant Sciences, 31(1): 2021, Page: 317-321

ISSN (print): 1018-7081; ISSN (online): 2309-8694

Short Communication

\title{
PHYSICOCHEMICAL PROPERTIES OF MAGNETIC WATER AND ITS EFFECT ON EGG PRODUCTION TRAITS IN HENS AT LATE LAYING PERIOD
}

\author{
M. I. El Sabry ${ }^{1 *}$, M. H. Abdelfattah ${ }^{2}$, H. A. Abdellatif ${ }^{2}$, S. E. Aggrey ${ }^{3}$ and S. S. Elnesr ${ }^{4}$ \\ ${ }^{1}$ Animal Production Department, Faculty of Agriculture, Cairo University, 6 El-Gamma St., 12613, Giza, Egypt; \\ ${ }^{2}$ Animal Production Researches Institute, Ministry of Agriculture and Land Reclamation, Dokki, Egypt; ${ }^{3}$ Department of \\ Poultry Science, University of Georgia, Athens 30602-2772, GA, USA; ${ }^{4}$ Department of Poultry Production, Faculty of \\ Agriculture, Fayoum University, 63514 Fayoum, Egypt \\ *Corresponding author Email: M.ELSABRY@daad-alumni.de
}

\begin{abstract}
This study was conducted to evaluate the egg production traits of laying hens receiving magnetic water (MW) for one month. Sixty Fayoumi hens at 54 weeks of age were used. On d 1 of the trial, hens were randomly assigned to control (non-magnetic water) and treatment (magnetic water, MW) groups. During the experiment, $\mathrm{pH}$ and electrical conductivity (EC) of water were recorded. The water nano-structure was investigated by electron microscopy. In parallel, egg mass, egg number, egg weight, egg production, and feed intake were recorded daily. Results showed that both $\mathrm{pH}$ and EC values of MW were higher compared to those of non-magnetic water $(\mathrm{P} \leq 0.05)$. In $\mathrm{MW}$, notable changes in the order and size of water molecules at the edge of water clusters were observed. Providing MW for the first two weeks did not affect any of productive traits. From third week of the experiment, egg production of MW group (34.5 $\pm 1.8 \%)$ was significantly higher than this $(27.8 \pm 2.1 \%)$ of control ones. In conclusion, physiochemical properties of MW may indirectly maintain hens' productivity in late age. Nevertheless, interdisciplinary investigations should be carried out to elucidate the mode of action of MW and probable side effects if any.
\end{abstract}

Keywords: magnetized water; magnetic field; egg production; egg weight; water properties.

https://doi.org/10.36899/JAPS.2021.1.0219

Published online August 26, 2020

\section{INTRODUCTION}

Water magnetization, as a clean and zero energy consumption application, has recently received a great interest in different fields. However, magnetic water (MW) is still a point of contention in different scientific societies. Magnetic water expression refers to magnetic field treated water that gains new properties. Alabi et al. (2015); El Sabry et al. (2018); Wang et al. (2018) stated that exposing water to a magnetic field induces several direct or indirect changes in electromagnetic, physical and chemical properties of water such as: $\mathrm{pH}$, electrical conductivity, surface tension, viscosity, boiling point, and molecular energy. Alabi et al. (2015) and Esmaeilnezhad et al. (2017) mentioned that there are number of theories to explain: what is magnetization, and how the magnetic field affects physiochemical properties of water.

Attributed to the new properties of MW, water magnetization application was suggested as an efficient eco-friendly solution for some industrial problems e.g. protecting the pipelines from corrosion, as an efficient scaling inhibitor and enhancing the efficacy of cooling systems (Esmaeilnezhad et al., 2017; Al Helal et al., 2018; Wang et al., 2018). In the biomedical field, provision of MW to rats for 30 days increased mineral density and mineral content of their bone compared to those of rats receiving non-magnetic water (Balieiro-Neto et al., 2017). In addition, providing MW to diabetic rats protected their kidneys from nephrotoxic damages as one of type 2 diabetes related complications (Zayed et al., 2018).

In animal production systems, using MW application is a point of contention because of the limited number of studies and their mixed results. For instance, Alhassani and Amin (2012) showed that broiler of the MW group (1 Tesla, $15 \mathrm{~min}$.) had superior results for feed conversion ratio and production index compared to the non-magnetic water group. In addition, the provision of the MW for laying hens improved the internal quality of eggs as well as the eggshell breaking strength (ElSabrout and Hanfy, 2017; El Sabry et al., 2018). ElHanoun et al. (2017) found that the MW improved the productive performance of geese. On the other hand, AlMufarrej et al. (2005) mentioned that providing MW to broiler chicks has no effect on their performance. These mixed results may be attributed to several factors such as the strength of magnetic field, duration of exposing water to magnetic field or the period of the study.

As the hen ages, egg production traits such as laying rate and egg quality decrese (Zita et al., 2012). Due to the potentiality of MW application, we hypothesized that providing MW to older laying hens may maintain or improve their productivity. Therefore, 
this study was conducted to evaluate the effect of magnetic field on water properties and subsequent effects on egg production percentage, egg weight, and feed intake of Fayoumi laying hens at the late laying period.

\section{MATERIALS AND METHODS}

Experimental animals: This study was approved by the Institutional Animal Care and Use Committee of Cairo University Protocol No. (CU-II-F-37-17). To avoid handling effect on hens, two weeks prior the start of the experiment, sixty Fayoumi hens were randomly assigned to control (non-magnetic water) and treatment (magnetic water, MW) groups, 30 hens per group. Hens were placed in individual cages in an open sided house (average of ambient temperature ranged from $24-26{ }^{\circ} \mathrm{C}$ ). At 54 weeks of age, on day 1 of the experiment, 3000 Gauss magnetic conditioner apparatus was attached only to the exterior surface of water pipeline of MW treated group. The experiment lasted for one month. All hens were provided with water and feed ad libitum. Laying hens were fed a diet containing $16 \%$ crude protein, 2700 $\mathrm{kcal} / \mathrm{kg}$ of metabolizable energy, $3.5 \%$ calcium, $0.42 \%$ available phosphorus.

Water measurements: Five water samples from each treatment were collected at days 1,15 and 30 of experiment to measure $\mathrm{pH}$ using $\mathrm{pH}$ meter (805 MP, FISHER, Germany) and electric conductivity (EC) using a conductivity meter (WTW LF315 Conductivity Meter, USA). At the end of the experiment (day 30), water samples were collected and negatively stained. Then, water were loaded on carbon-coated grids and air-dried to be ready for investigation by electron microscope (JEOL JEM-1400, USA). It was assumed that the pattern of distribution of dye precipitation and stained salts may demonstrate the physical changes in water molecules.

Egg production traits: Daily egg production and egg weight for each hen were recorded throughout the experimental period. Then, egg mass, average egg weight and egg production percentage during the $1^{\text {st }}$ half of the experiment (d1-15), the second half of the experiment (d16-d30) and overall experimental period (d1-d30) were calculated as follow:

Egg mass (g) (d1-15), (d16-30), (d1-30) = $\sum$ eggs'

weight.

Average egg weight $(\mathrm{g})(\mathrm{d} 1-15),(\mathrm{d} 16-30),(\mathrm{d} 1-30)=$ total eggs' weight / number of eggs.

Egg production $(\%)(\mathrm{d} 1-15),(\mathrm{d} 16-30),(\mathrm{d} 1-30)=\mathrm{Egg}$ number/period*100.

Daily feed intake $=$ Total feed intake all over experimental period/30days

Statistical analysis: The data on water $\mathrm{pH}$ and $\mathrm{EC}$ were were collected and analysed using JMP pro 5 statistical software (2005). The egg production data were analyzed from day 1-15, day 16-30 and day 1-30. The t-test was applied to compare between the properties of MW and non-magnetic water. It was also used to compare the productive parameters of hens receiving $\mathrm{MW}$ or nonmagnetic water.

\section{RESULTS AND DISCUSSION}

Changes in water properties: The MW application is eco-friendly, zero energy consumption and costless when a permanent magnet is used. Magnetized water can be made by passing water through a magnetic field. Results showed that the $\mathrm{pH}$ of MW $(7.03 \pm 0.00)$ was higher than the $\mathrm{pH}$ of non-magnetic water $(6.76 \pm 0.07)$ during the experimental period $(\mathrm{P} \leq 0.05)$. Also, the $\mathrm{EC}$ of the $\mathrm{MW}$ $(422.14 \pm 1.46)$ was higher $(\mathrm{P} \leq 0.05)$ than those of nonmagnetic water $(394.28 \pm 1.97)$. These changes in water $\mathrm{pH}$ and $\mathrm{EC}$ were determined to ensure that the hens were contentiously receiving magnetic water throughout the experimental period. Also, Yacout et al. (2015) recorded similar $\mathrm{pH}$ and $\mathrm{EC}$ values during his study on goats.

Kotb (2013) suggested that the atoms' nuclei in the water are polarized under the magnetic field and then those atoms act as tiny magnets. Moreover, he suggested that the increase in $\mathrm{pH}$ value is due to the polarization and the uniform order of atoms. However, Gaafar et al. (2015) observed that an increase in EC of tap water under magnetic field (3000 - 5000 Gauss) at variable exposure times $(\mathrm{t} \leq 10 \mathrm{~min})$. The alteration in the water EC may be due to:1) the changes in the ions' charge and velocity of $\mathrm{H}+$ ions or 2) the dipole moments of free molecules and clusters, including H-bond chains of the water under the effect of magnetic fields (Pang and Shen, 2013). They added that these chemical changes also may result in alterations in the physical structure of water.

The microscopic images showed that the magnetic field affected the nanostructure of MW (Figure 1)., It is clear that the molecules of the MW cluster were well ordered as opposed to the molecules of nonmagnetic water, which were not well-ordered. Also, the MW molecules were smaller than those of non-magnetic water, specialy, at the edges of water clusters.. The change in the physical structure of water under magnetic field application has been reported and different theories gave different explanations. For instance, Chang and Weng (2006) suggested that the better order of the water molecules and bigger size of water clusters under applied magnetic field might be due to the increase in the number of hydrogen bonds. The micrographs of the dye precipitations showed the pattern of the effect of the magnetic field on the water (Figure 1). From both literature and the current study, there is a clear relation between chemical and physical properties of the MW. 


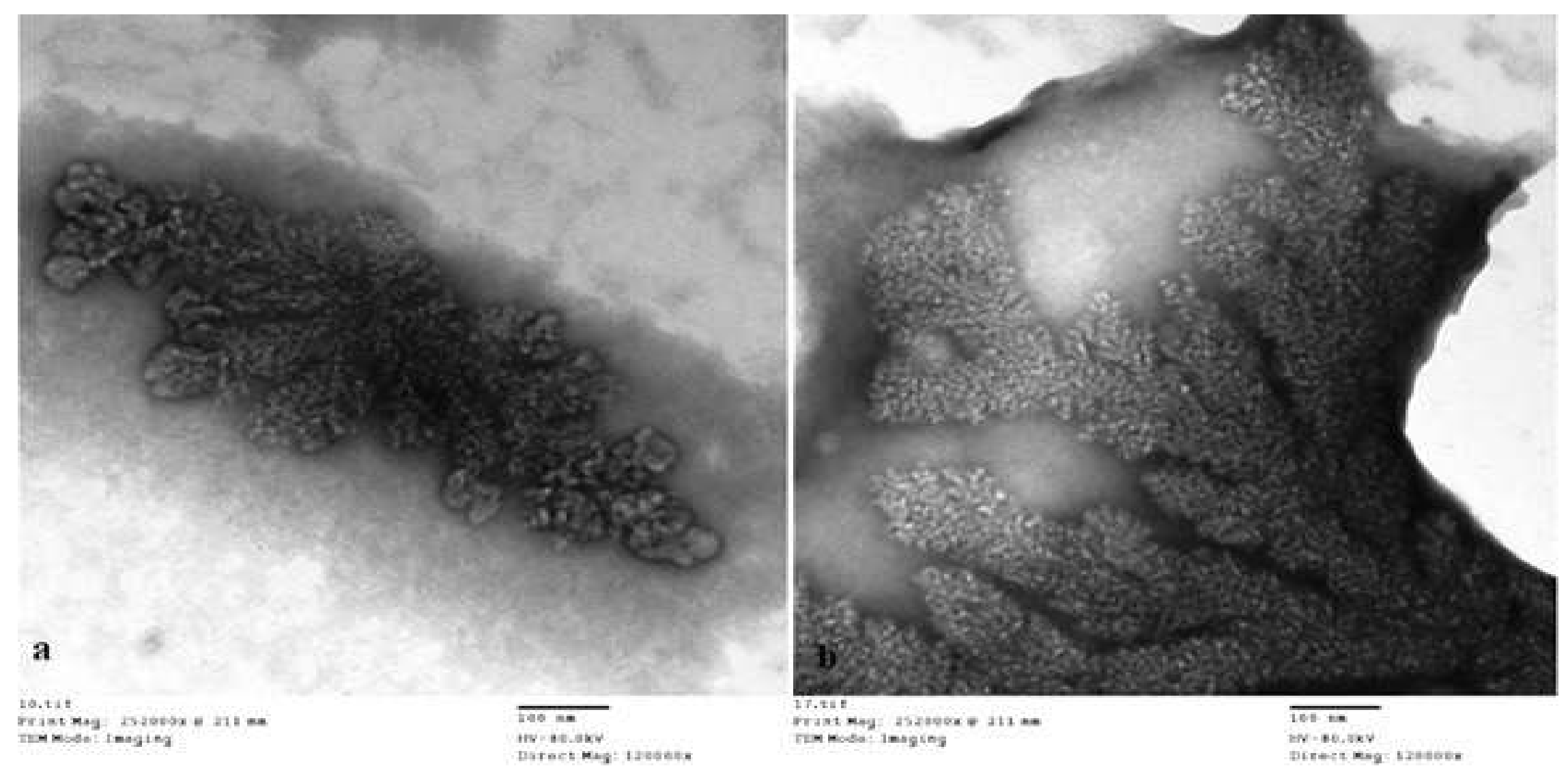

Figure 1. a) molecules of non-magnetic were not well ordered and big in size at the edge of water clusters (b) molecules of magnetic water were well ordered and small in size (electron microscope, 120000X).

Table 1. Effect of magnetic water (MW) and non-magnetic water (control) on egg production traits $( \pm \mathrm{SE})$ in Fayoumi hens at late laying period.

\begin{tabular}{|c|c|c|c|c|c|c|c|c|c|c|c|c|}
\hline \multirow{2}{*}{$\begin{array}{l}\text { Trait } \\
\text { Days }\end{array}$} & \multicolumn{2}{|c|}{ Egg number } & \multicolumn{4}{|c|}{ Egg mass (g) } & \multicolumn{2}{|c|}{ Egg weight (g) } & \multicolumn{4}{|c|}{ Egg production (\%) } \\
\hline & MW & Control & $\begin{array}{c}p- \\
\text { value }\end{array}$ & MW & Control & $p$-value & MW & Control & $p$-value & MW & Control & $\begin{array}{c}p- \\
\text { value }\end{array}$ \\
\hline $1-15$ & $4.5 \pm 0.2$ & $4.4 \pm 0.3$ & 0.94 & $208.6 \pm 14.2$ & $201.5 \pm 15.2$ & 0.73 & $45.9 \pm 0.6$ & $44.8 \pm 0.6$ & 0.24 & $30.1 \pm 1.9$ & $29.8 \pm 2.1$ & 0.93 \\
\hline $16-30$ & $5.5 \pm 0.4^{\mathrm{a}}$ & $4.1 \pm 0.4^{\mathrm{b}}$ & 0.03 & $270.7 \pm 21.0^{\mathrm{a}}$ & $191.9 \pm 22.8^{\mathrm{b}}$ & 0.01 & $48.7 \pm 0.7^{\mathrm{a}}$ & $44.8 \pm 0.7^{\mathrm{b}}$ & 0.00 & $34.5 \pm 1.8^{\mathrm{a}}$ & $27.8 \pm 2.1^{\mathrm{b}}$ & 0.04 \\
\hline $1-30$ & $10.0 \pm 0.5$ & $8.5 \pm 0.5$ & 0.07 & $479.3 \pm 27.4^{\mathrm{a}}$ & $392.5 \pm 28.7^{\mathrm{b}}$ & 0.03 & $47.5 \pm 0.6^{\mathrm{a}}$ & $45.5 \pm 0.6^{\mathrm{b}}$ & 0.04 & $32.3 \pm 1.8$ & $28.5 \pm 1.9$ & 0.07 \\
\hline
\end{tabular}


Egg production traits: Fayoumi breed is a native Egyptian one that is able to survive under harsh nutritional and environmental conditions (El Sabry et al., 2012). Schilling et al. (2019) stated that Fayoumi breed is less vulnerable to numerous poultry diseases including Newcastle disease, when comparision with other breeds. However, Fayoumi breed has relatively lower egg production compared with other commercial breeds. For instance, the peak of egg production \%, at $30-40$ weeks of age, ranges between (49.5 - 56\%). The total egg production (hen per year) is around 130 eggs under rural condition or around 141 eggs under intensive condition (Sazzad, 1992; Khan et al., 2006). It is therefore timely to investigate the efficacy of using MW to improve the performance of the Fayoumi hens.

Mgnetic water presents one of the recent trends to enhance livestock production. In the current study, from day 1-15 of the experiment, egg number, egg mass, average egg weight and egg production \% of both treatments were similar (Table 1). However, from 16-30 days, the egg number, egg mass, average egg weight and egg production \% of the hens of MW group were significantly higher as compared to the hens of nonmagnetic water group. Balieiro-Neto et al. (2017), also reported that providing MW to growing rats for 15 days did not improve the bone mineral density and bone mineral content, but providing MW for 30 days to rats resulted in a significant increase in the bone mineral density and bone mineral content. Taken together, perhaps providing MW for a longer period could positively affect hens' performance.

The overall results through the experimental period (1-30 days) showed that laying receiving MW exhibited superior results for egg weight and mass compared to those of hens receiving non-magnetic drinking water (Table 1), which indicates to accumulation effects of MW treatment on the productivity. Moreover, daily feed intake $(120.6 \pm 0.9 \mathrm{~g})$ of hens of MW group was greater than feed intake $(116.2 \pm 0.8)$ of hens of control group $(\mathrm{P}=0.0008)$. This greater feed consumption can be associated with the increase in the productivity of laying hens provided with MW.

Unfortunately, the available data on the effect of MW on the performance of laying hens are scant. ElSabrout and Hanfy (2017) and El Sabry et al. (2018) found that the MW significantly improved internal egg quality and eggshell quality without any effect on layers productivity or egg weight. This inconsistency between the results ofprevious studies and present onse can be attributed to the genetic composition of breeds, age of flocks as well as the variation in experimental conditions. Generally, it appears that the change in MW properties have beneficial effects on the egg production.

Magnetic water has been shown to alter the $\mathrm{pH}$ of water to neutral or alkaline, which can mitigate the effects of oxidative stress. For example, Zayed et al.
(2018) found that providing MW to type 2 diabetic rats can reduce oxidative stress, hyperlipidemia, uremia, and renal dysfunction. In human, Weidman et al. (2016) reported a relation between oxidative stress and blood viscosity. They reported a significant difference in whole blood viscosity when assessing an alkaline water versus a standard purified water during the recovery phase after exercise-induced dehydration. Therefore, it is plausible to suggest that the increase in $\mathrm{pH}$ value of $\mathrm{MW}$ can be a tool to modulate the stress physiology of laying hens and subsequently enhance performance.

Conclusion: From the data of the current study, it can be concluded that alteration in MW properties could indirectly influence the egg production traits. However, it appears that the effect of magnetic water on performance depends on the duration of provision of the MW treatment.

Acknowledgements: The authors extend thanks to their respected institutes and universities.

Conflict of interest: The authors declare no conflict of interest.

Animal welfare statement:Animal care and maintenance were performed in accordance with guidelines of Egyptian Research Ethics Committee. This study was approved by the Institutional Animal Care and Use Committee of Cairo University Protocol No. (CU-IIF-37-17).

\section{REFERENCES}

Al Helal, A., A. Soames, R. Gubner, S.I. glauer and A. Barifcani (2018). Influence of magnetic fields on calcium carbonate scaling in aqueous solutions at $150^{\circ} \mathrm{C}$ and $1 \mathrm{bar}$. J. Colloid Interface Sci. 509: 472-484,

Alabi, A., M. Chiesa, C. Garlisi and G. Palmisano (2015). Advances in anti-scale magnetic water treatment.Environ. Sci.: Water Res. Technol. 1: 408-425. doi: 10.1039/C5EW00052A

Alhassani, D.H. and G.S. Amin (2012). Response of some productive traits of broiler chickens to magnetic water. Int. J. Poult. Sci. 11 (2): 158160. doi:10.3923/ijps.2012.158.160

Al-Mufarrej, S., H.A. Al-Batshan, M.I. Shalaby and T.M. Shafey (2005). The effects of magnetically treated water on the performance and immune system of broiler chickens. Int. J. Poult. Sci. 4 (2): 96-102. doi: 10.3923/ijps.2005.96.102

Balieiro-Neto, G., J.R. Engracia Filho, B.R.S.M. de Oliveira, C.M.M. Coelho, L.F.A. de Souza and M.J.Q. Louzada (2017). Water treatment by magnetic field increases bone mineral density of rats. J. Clin. Densitom. 20(4): 526-531. 
Chang, K.T. and C.I. Weng (2006). The effect of an external magnetic field on the structure of liquid water using molecular dynamics simulation. J Appl. Phys. 100 (4): 043917.

El Sabry M.I., A.M.M. Atta, B. Tzschentke, H.B.A. Gharib and F.K.R. Stino (2012). Potential use of interleukin-2-rich supernatant adjuvant in Fayoumi hens. Arch. Gefluegelkd 76 (3): 162167.

El Sabry, M.I., J.W. Charal, K.W. McMillin and T.A. Lavergne (2018). Does magnetized drinking water affect productivity and egg quality of layers? Egy. J. Anim. Prod. 55 (2): 117-123.

El-Hanoun, A.M., Y.A. Attia, M.A. Al-Harthi, H.I. Habiba and M.C. de Oliveira (2017). Magnetized drinking water improves productivity and blood parameters in geese. Rev. Colomb. Cienc. Pecu. 30 (3): 209-218. http://dx.doi.org/10.17533/udea.rccp.v30n3a04

El-Sabrout, K. and M. Hanafy (2017). Effect of magnetized water on productive traits of laying chickens. The Professional Animal Scientist (PAS). 33 (6): 739-742.

Esmaeilnezhad, E., H.J. Choi, M. Schaffie, M. Gholizadeh and M. Ranjbar (2017). Characteristics and applications of magnetized water as a green technology. J. Clean. Prod. 161: 908-921.

Gaafar, M.M., H.J. Hussain, K.A. Chaloob, S. Niehad Raheem and S.K.A.B. Mohamed (2015). Effect of magnetic water on physical properties of different kind of water, and studying its ability to dissolving kidney stone. J. Nat. Sci. Res. 5: 85-94.

Khan, M.K.I., M.J. Khatun, M.S.A. Bhuiyan and R. Sharmin (2006). Production performance of Fayoumi chicken under intensive management. Pakistan J. Biol. Sci. 9 (2): 179-181.

Kotb, A. (2013). Magnetized Water and Memory Meter. Energy and Power Engineering. 5: 422-426.

Pang, X.F. and G.F. Shen (2013). The changes of physical properties of water arising from the magnetic field and its mechanism. Mod. Phys. Lett. B. 27 (31): 1350228.

Sazzad, M.H. (1992). Comparative study on egg production and feed efficiency of different breeds of poultry under intensive and rural conditions in Bangladesh. Livestock Res. Rural. 4 (3): 65-69.

Schilling, M.A., S. Memari, M. Cavanaugh, R. Katani, M. S. Deist, J. Radzio-Basu, S.J. Lamont, J.J. Buza and V. Kapur (2019). Conserved, breeddependent, and subline-dependent innate immune responses of Fayoumi and Leghorn chicken embryos to Newcastle disease virus infection. Sci. Rep. 9: Article No.: 7209.

Statistical software (JMP pro 5) (2005). SAS Institute Inc., Cary, North Carolina, USA.

Wang, Y., H. Wei and Z. Li (2018). Effect of magnetic field on the physical properties of water. Res. Phys. 8: 262-267. doi:10.1016/j.rinp.2017.12.022

Weidman, J., R.E. Holsworth, B. Brossman, D.J. Cho, J.S. Cyr and G. Fridman(2016). Effect of electrolyzed high-pH alkaline water on blood viscosity in healthy adults. J. Int. Soc. Sports Nutr. 13 (1): 45. doi:10.1186/s12970-016-01538

Yacout, M.H., A.A. Hassan, M.S. Khalel, A.M. Shwerab and E.I. Abdel-Gawad (2015). Effect of magnetic water on the performance of lactating goats. J. Dairy Vet. Anim. Res. 2 (5): 159-170.

Zayed, A.E., A. Saleh, A. Gomaa, M. Abd-Elkareem, M.M. Anwar, K. Hassanein, M.M. Elsherbiny and A.M. Kotb (2018). Protective effect of Ginkgo biloba and magnetized water on nephropathy in induced type 2 diabetes in rat. Oxid. Med. Cell. Longevity. Article ID 1785614, 10 pages.

Zita, L., Z. Ledvinka, E. Tumova and L. Klesalova (2012). Technological quality of eggs in relation to the age of laying hens and Japanese quails. Rev. Bras. Zootecn. 41(9): 2079-2084. 